\title{
THE ROLE OF SURFACE ROLLERS ON THE FORMATION OF SURFZONE TRANSVERSE SAND BARS
}

\author{
Francesca Ribas ${ }^{1}$, H.E. de Swart $^{2}$, Daniel Calvete ${ }^{3}$ and Albert Falqués ${ }^{4}$
}

\begin{abstract}
A morphodynamic model has been developed to gain more fundamental knowledge about the formation of transverse finger sand bars. The model describes the feedback between waves, rollers, depth-averaged currents and bed evolution, so that self-organized processes can develop. The wave and bathymetric conditions measured at Egmond site are firstly applied and the modeled longshore current and wave height are compared with field data of that beach. Subsequently, the wave and bathymetric conditions measured at Noordwijk site are used to compare model results with the up-current oriented bars observed there. Realistic positive feedback leading to formation of the observed bars only occurs if the resuspension of sediment due to bore turbulence is included in the model. The modeled wavelength, crest orientation and growth rate agree with data but the model overestimates the migration rates.
\end{abstract}

Key words: morphodynamics, sediment transport, nearshore bars, surface rollers

\section{Introduction}

Patches of transverse sand bars have been observed in the surf zone of several beaches, spaced with a remarkable alongshore periodicity (from 15 to $200 \mathrm{~m}$ ). These bars are thin and elongated accumulations of sand attached to the shoreline, which extend inside the surf zone with a shore-normal or shore-oblique orientation. They emerge on gently sloping beaches (slope $<0.02$ ), both in microtidal sheltered areas (e.g. Gelfenbaum and Brooks, 2003) and on mesotidal more energetic open coasts (e.g. Konicki and Holman, 2000). A patch of transverse bars with a wavelength of $45 \mathrm{~m}$, observed during August and September 2002 at Noordwijk beach (the Netherlands), is shown in figure 1 (see Ribas and Kroon, 2007). These types of bars were named 'transverse finger bars' in order to emphasize the differences with other types of transverse bars, like those in the 'Transverse bar and rip state' of Wright and Short (1984). The latter were a result of the welding to the shore of a crescentic bar, a different origin from that of the bars at Noordwijk.

Konicki and Holman (2000) and Ribas and Kroon (2007) used hourly time-averaged video-images to describe the characteristics of transverse finger bars in Duck (USA) and in Noordwijk (the Netherlands), respectively (figure 1). One to three shore-parallel subtidal bars are very often present in these beaches, sometimes showing a crescentic shape (van Enckevort et al. 2004). The detected bars were most often located inside the trough of the inner bar, attached to the low-tide shoreline. That is why Konicki and Holman (2000) named them 'trough bars'. Both the percentage of days with patches and the number of bars per patch were significantly larger in Noordwijk. The overall averaged wave length was $39 \mathrm{~m}$ in Noordwijk bars and $79 \mathrm{~m}$ in Duck 'trough bars'. In Noordwijk, bar crests deviated from the shore-normal by some $30^{\circ}$ and bar patches migrated as a whole at rates up to a few tens of meters per day. Ribas and Kroon (2007) also correlated the characteristics of Noordwijk bars with the hourly wave conditions (measured by an offshore buoy at $18 \mathrm{~m}$ water depth). Bar patches migrated in the direction of the longshore current and bar crests deviated from the shore-normal in the up-flow direction ('up-current orientation'). Wave conditions detected in Noordwijk during bar presence were characterized as intermediate waves (root mean square wave height, $\left.H_{r m s} \approx 0.75 \mathrm{~m}\right)$ with large angles of incidence with respect to the shore-normal $\left(\theta_{\text {off }} \approx 50^{\circ}\right)$.

\footnotetext{
${ }^{1}$ Department of Applied Physics, Escola Politècnica Superior de Castelldefels, Universitat Politècnica de Catalunya, Campus del Baix Llobregat, Avinguda del Canal Olímpic 15, 08860 Castelldefels, Spain. cesca@fa.upc.edu

2 IMAU, Utrecht University, Princetonplein 5, 3584 CC Utrecht, the Netherlands, h.e.deswart@uu.nl

3 Dept. Applied Physics, Univ. Politècnica de Catalunya, 08034 Barcelona, Spain. calvete@fa.upc.edu

${ }^{4}$ Dept. Applied Physics, Univ. Politècnica de Catalunya, 08034 Barcelona, Spain. falques@fa.upc.edu
} 


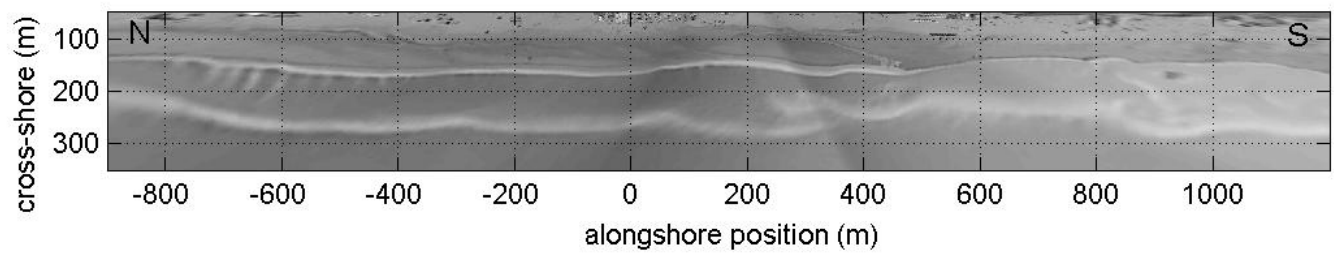

Figure 1. Patch of transverse finger sand bars observed at Noordwijk beach on 27 august 2002. In this planview, built from a combination of five time-averaged oblique images from video cameras, the white stripes are due to preferential

wave breaking on the shallows and indicate nearshore bar presence. Waves come from the bottom left corner.

A possible explanation for the formation of this type of transverse finger bars is based on the concept of morphodynamic self-organization. Topographic perturbations superimposed on an alongshore uniform beach induce hydrodynamic perturbations, which can lead to convergence of sand transport over the bars, hence producing a positive feedback. Linear stability analysis is a useful tool to investigate the possible feedbacks, yielding information about the shape, the growth rate and the migration speed of the initially emerging modes. It also allows for a systematic exploration of the sensitivity of bar characteristics to the beach conditions and to the model formulation of different physical processes. Nonlinear models are used to describe the finite-amplitude features and verify the results of the linear stability analysis. Several selforganization models for transverse bar formation have been developed in the last years (Ribas et al. 2003; Ribas et al. 2005; Garnier et al. 2006). They demonstrated that self-organization can explain bar formation since the computed topographic patterns resemble transverse bars in nature. However, the predicted shapes (orientation of oblique bars with respect to the longshore current) and the time scales for growth and migration strongly depended on the specific description of wave propagation and sediment transport. Performing a quantitative comparison with field observations is essential to test these models, verify the available predictions for bar characteristics and clarify the remaining open questions.

The study of Ribas and Kroon (2007) used the field observations at Noordwijk to test the predictions of the existing idealized self-organization models for transverse bar formation. Considering that Noordwijk bars were up-current oriented and that they emerged during periods of clearly oblique wave incidence, only the 'bed-flow mechanism', first described by Ribas et al. (2003), remained as a viable explanation for their formation. Their crucial assumption is related to the cross-shore distribution of the depth-averaged volumetric sediment concentration, $C_{d a}$. Only when $C_{d a}$ decreases seaward in the inner surf zone, upcurrent oriented bars can emerge. As explained in Ribas et al. (2003), the 'bed-flow coupling' is dominant in case of $\theta_{\text {off }}$ larger than some $10^{\circ}$, the presence of strong longshore currents being essential. The growing bars locally modify the longshore current, which veers towards the direction of maximum topographic gradient due to mass conservation. Hence offshore deflection takes place over up-current oriented bars. Positive feedback only occurs if $C_{d a}$ decreases seaward because this enhances the convergence of sediment flux in offshore-directed flows.

Ribas et al. (2003) presented a simplified model that included the bed-flow mechanism and predicted the formation of up-current oriented bars. It was based on linear stability analysis and a highly-idealized formulation for the beach geometry (constant sloping beach), the wave transformation (regular wave height and no shoaling effects) and the sediment transport (spatially uniform depth-integrated sediment concentration). A more accurate wave transformation was included in Ribas et al. (2005), with random wave heights and shoaling effects, and the up-current bars remained as a robust outcome. Finally, Garnier et al. (2006) studied the non-linear temporal evolution of up-current oriented bars. The wave transformation was similar to that of Ribas et al. (2005), the sediment transport included a spatially uniform depth-integrated concentration and the initial beach profile was constant sloping. The modeled bars emerged and reached finite amplitudes at values around $30 \mathrm{~cm}$.

The aim of the present contribution is to model and understand the role of surface rollers on the formation of up-current oriented surfzone bars using a more realistic model. In particular, the cross-shore distribution of $C_{d a}$ should come from a physical model that describes the stirring of sediment by waves and currents. Rollers can play a crucial role because they create turbulent bores that can lead to significant sediment resuspension in the inner surf zone. This may give a cross-shore distribution of $C_{d a}$ that could 
explain the formation of up-current bars. Including the roller dynamics also allows to properly describe the cross-shore distribution of the longshore current (Ruessink at al., 2001). We use the up-to-date selforganization model described in Calvete et al. (2005), based on stability analysis, after extending it to include rollers and turbulent resuspension in the inner surf zone.

Before modeling the formation of nearshore bars, it is important to validate the reference basic state with field data (especially the cross-shore distribution of the longshore current). Thereby, the first step of the present study, performed in section 3, is applying the model to the conditions measured at Egmond beach (the Netherlands) in order to compare the modeled reference longshore current and wave height with field data collected there on autumn 1998 (field measurements of these quantities are not available at Noordwijk site). A detailed model-data comparison using these Egmond data was also performed by Ruessink et al. (2001) and they concluded that including the rollers was essential to reproduce the correct cross-shore location of the longshore current maximum. In section 4, the model is applied to the conditions measured at Noordwijk beach during the observation of up-current oriented bars on August-September 2002.

\section{Model}

The model describes the feedback between wave and roller dynamics, depth-averaged currents and bed evolution, so that self-organized processes can develop. The $y$ (or $x_{2}$ ) axis is chosen to coincide with the rectilinear shoreline, the $x$ (or $x_{1}$ ) axis points in the seaward direction and the $z$ axis points upwards.

\subsection{Hydrodynamics}

Waves are assumed to have a narrow spectrum in frequency and angle. Their heights are supposed to be random and follow the Rayleigh distribution, characterized by the root mean square wave height, $H_{r m s}$ (wave energy being $E=\rho g H_{r m s}^{2} / 8$, where $\rho$ is the water density and $g$ is gravity). When waves approach the coast, their evolution is described using linear wave theory, which yields expressions for the wave properties such as the radiation stresses, $S^{w}{ }_{i j}$, the root mean square wave orbital velocity amplitude, $u_{r m s}$, and the two components of the group and phase velocity, $c_{g i}$ and $c_{i}$. The dispersion relation for the intrinsic wave frequency is also computed with the standard linear wave theory. When introducing the Doppler shift to relate the intrinsic frequency to the absolute frequency, $\Omega$, the following relation is obtained,

$$
\Omega=\sqrt{g|\vec{K}| \tanh (|\vec{K}| D)}+v_{j} K_{j}, \quad j=1,2 \quad \text {. }
$$

Here, $K_{i}$ are the two components of the wave number, $v_{i}$ are the two components of the depth-averaged fluid velocity and $D=z_{s}-z_{b}$ is the water depth, where $z_{s}$ is the mean free surface elevation and $z_{b}$ is the sea bottom level. Steady conditions are assumed, $\Omega=$ constant. Equation (1) is finally rewritten in terms of the wave phase $\Phi$, from which $K_{i}$ and thereby $\theta$ can be computed. This equation describes the refraction of the waves due to both topography and currents. More complex processes in wave propagation, like wave diffraction, are not accounted for.

Wave energy balance is described with a wave- and depth-averaged equation (with wave-current interactions),

$$
\frac{\partial E}{\partial t}+\frac{\partial}{\partial x_{j}}\left(\left(v_{j}+c_{g j}\right) E\right)+S_{j k}^{w} \frac{\partial v_{k}}{\partial x_{j}}=-\mathrm{D}_{w} \quad, \quad j, k=1,2
$$

The energy dissipation rate due to wave breaking, $\star_{w}$, is parameterized using the two following different formulations,

$$
\mathrm{D}_{w}^{\mathrm{a}}=\frac{3 B^{3} \rho g \Omega H_{r m s}^{5}}{32 \sqrt{\pi} \gamma_{b}^{2} D^{3}}\left(1-\left(1+\left(\frac{H_{r m s}}{\gamma_{b} D}\right)^{2}\right)^{-2.5}\right)
$$




$$
\mathrm{D}_{w}^{\mathrm{b}}=\frac{3 B^{3} \rho g \Omega H_{r m s}^{3}}{32 \sqrt{\pi} D}\left(1-\left(1+\left(\frac{H_{r m s}}{\gamma_{b} D}\right)^{2}\right)^{-2.5}\right)\left(1+\tanh \left(8\left(\frac{H_{r m s}}{\gamma_{b} D}\right)\right)\right)
$$

where $B$ is a dissipation parameter describing the type of breaking and $\gamma_{b}$ is the coefficient of saturation condition (i.e., the expected saturation value of $H_{r m s} / D$ ). The formulation $\Sigma_{v}{ }^{a}$ is the one developed by Thornton and Guza (1983). Church and Thornton (1993) used a similar formulation, $\star_{v}^{b}$, which included a different weighting function such that ${ }_{\alpha_{v}}^{b} \rightarrow 0$ for large $D / H_{r m s}$, and well-reproduced the wave height distribution in Duck (U.S.A.) during DELILAH experiment. The values that were recommended for $B$ and $\gamma_{b}$ varied slightly for the two formulations (Thornton and Guza, 1983; Church and Thornton, 1993). Here we use $B=1$ and $\gamma_{b}=0.45$ for ${ }_{\otimes_{v}}{ }^{a}$ in (3) and $B=1.3$ and $\gamma_{b}=0.38$ for $\otimes_{v}{ }^{b}$ in (4).

The energy dissipated by breaking feeds the surface rollers, i.e. the aerated mass of water located on the shoreward face of breaking waves. The wave- and depth-averaged roller energy balance is an extension of the one proposed by Reniers et al. (2004),

$$
\frac{\partial\left(2 E_{r}\right)}{\partial t}+\frac{\partial}{\partial x_{j}}\left(2\left(v_{j}+c_{j}\right) E_{r}\right)+S_{j k}^{r} \frac{\partial v_{k}}{\partial x_{j}}=-\mathrm{D}_{r}+\mathrm{D}_{w}, \quad j, k=1,2,
$$

where $E_{r}$ is the energy of the roller and $S_{i j}^{r}$ are the radiation stresses due to roller propagation computed following Svendsen (1984). Finally, the roller energy dissipation rate, $₫$, is modeled following Ruessink et al. (2001), with a standard value for the slope of the roller/wave front, $\beta=0.05$. Wave conditions are prescribed offshore $\left(H_{r m s, o f f}, \theta_{\text {off }}\right.$ and $\Omega=2 \pi / T_{p}$, where $T_{p}$ is the peak period), where $E_{r}$ is assumed to be zero. The offshore boundary is located at the water depth where the buoys are located in the corresponding sites (16 $\mathrm{m}$ depth at Egmond site and $18 \mathrm{~m}$ depth at Noordwijk site).

The large-scale fluid motions are governed by the wave- and depth-averaged mass and momentum balance equations, where the radiation stresses due to both wave and roller propagation are included,

$$
\begin{array}{cc}
\frac{\partial D}{\partial t}+\frac{\partial}{\partial x_{j}}\left(D v_{j}\right)=0 & , \quad j=1,2 \\
\frac{\partial v_{i}}{\partial t}+v_{j} \frac{\partial v_{i}}{\partial x_{j}}=-g \frac{\partial z_{s}}{\partial x_{i}}-\frac{1}{\rho D} \frac{\partial}{\partial x_{j}}\left(S_{i j}^{w}+S_{i j}^{r}-S_{i j}^{t}\right)-\frac{\tau_{b i}}{\rho D} \quad, \quad i, j=1,2
\end{array}
$$

where, $\tau_{b i}$ are the bed shear stresses, and $S_{i j}^{t}$ are the turbulent Reynolds stresses.

The bed shear stresses are parameterized following the generalized equation developed by Feddersen et al. (2000), which we have extended to model the effect of a 2-dimensional flow,

$$
\tau_{b i}=\rho c_{D} \frac{u_{r m s}}{\sqrt{2}} v_{i}\left(1.16^{2}+2 \frac{|\vec{v}|^{2}}{u_{r m s}^{2}}\right) \quad, \quad i=1,2,
$$

where, $c_{D}$ is the drag coefficient. According to Feddersen et al. (2000) and Ruessink et al. (2001), this empirical parameterization adequately represents the shear stresses for the random wave field at both Duck and Egmond beaches, respectively. The drag coefficient $c_{D}$ is the dimensionless friction coefficient due to current and waves and is assumed to vary with depth following the Manning-Strickler law (Soulsby 1997), where the bed roughness, $k_{a}$, is assumed to be constant in time and space. The default value for the bed roughness is $k_{a}=0.022 \mathrm{~m}$, a value obtained by Ruessink et al. (2001) after calibration with Egmond data. The turbulent Reynolds stresses, $S_{i j}^{t}$ in equation (7), are modeled with the standard eddy viscosity approach. The lateral turbulent mixing coefficient is directly linked to the roller energy dissipation (the main source of turbulence), $v_{t}=M(\bowtie / \rho)^{1 / 3}$, where $M=1$. The fluid velocities are imposed to vanish at both the coastline and the offshore boundary. Also, the free surface elevation must vanish far offshore. 
Coastal Dynamics 2009

Paper No.55

\subsection{Sediment transport}

Conservation of sediment mass yields the bottom evolution equation

$$
(1-p) \frac{\partial z_{b}}{\partial t}+\frac{\partial q_{j}}{\partial x_{j}}=0 \quad, \quad j=1,2
$$

with $p=0.4$ being the porosity of the bed and $q_{i}$ the two components of the wave- and depth-averaged volumetric sediment transport $\left(\mathrm{m}^{2} / \mathrm{s}\right)$. A widely accepted formulation for $q_{i}$ in the nearshore is that of Soulsby and van Rijn (Soulsby, 1997). Their original expression has been extended to model the effect of a 2-dimensional flow and the preferred downslope transport of the sand,

$$
q_{i}=C_{d i}\left(v_{i}-\Gamma \frac{\partial h}{\partial x_{i}}\right) \quad, \quad i=1,2
$$

where $C_{d i}$ is the depth-integrated volumetric sediment concentration. The bedslope coefficient $\Gamma$ is modeled following Calvete et al. (2005), $\Gamma=u_{r m s}$. The corresponding term accounts for the tendency of the system to smooth out the sea bed perturbations, $h$, if the latter do not cause positive feedback into the flow. We have also extended Soulsby and van Rijn formula to include the extra contribution to $C_{d i}$ due to the stirring of sediment created by the bore induced turbulence,

$$
C_{d i}=A_{s}\left(\left(|\vec{v}|^{2}+\frac{0.018}{c_{D}} u_{r m s}^{2}\right)^{0.5}-u_{c r i t}\right)^{2.4}+\frac{\varepsilon_{b o r}}{w_{s} g(s-1)} \frac{\mathrm{D}_{r}}{\rho}\left(e^{\left(D / H_{r m s}\right)}-1\right)^{-1.5}
$$

where $u_{\text {crit }}$ is the threshold flow intensity for sediment transport, the parameter $A_{s}$ accounts for the sediment properties, $w_{s}$ is the sediment fall velocity, $s=2.65$ is the relative density of the sediment and $\varepsilon_{b o r}$ is the suspended load efficiency related to bore-induced turbulence (i.e., the fraction of the total power produced by turbulent motion that is expended in sediment resuspension, assumed to be constant). In the original Soulsby van Rijn formula, $C_{d i}$ was assumed to be a result of the shear stresses produced in the bottom boundary layer of the wave orbital velocity and the depth-averaged currents (first term in equation 11). The SvR-formula was tested to be accurate in the shoaling domain, at water depths of the order of $5 \mathrm{~m}$ (Soulsby, 1997). However, in the inner surf zone (depths $<1 \mathrm{~m}$ ), where $u_{r m s}$ and the longshore current decay, other processes like bore propagation and the created turbulence also produce significant sediment resuspension (Voulgaris and Collins, 2000; Butt et al., 2004). In the present study, the second term in equation (11) has been added to allow inclusion of these other possible processes. We follow Roelvink and Stive (1989), who assumed that this extra $C_{d i}$ was proportional to the dissipation of roller energy (similary also to Kobayashi et al., 2008), where the suspended load efficiency $\varepsilon_{b o r}$ was of $\mathrm{O}\left(10^{-2}\right)$. By varying $\varepsilon_{b o r}$, we can change the strength of the sediment resuspension due to bore induced turbulence. A default value $\varepsilon_{b o r}=0.025$ is used, which gives reasonables values of $C_{d i}$ of some $510^{-4} \mathrm{~m}$ in the inner surf zone. The original Soulsby van Rijn $C_{d i}$ is obtained for $\varepsilon_{b o r}=0$. The fall velocity, $w_{s}$, is computed from the sediment grain size $d_{50}$ (following Soulsby, 1997). The Manning-Strickler law is again assumed for the drag coefficient $c_{D}$ and the full expressions for $u_{c r i t}$ and $A_{s}$ are given in Soulsby (1997).

Table 1. Field conditions during the three selected bursts measured at Egmond.

\begin{tabular}{|c|c|c|c|c|c|}
\hline \multirow{2}{*}{$\begin{array}{c}\text { Burst } \\
\text { number }\end{array}$} & \multirow{2}{*}{ Date and time } & \multicolumn{4}{|c|}{ Wave conditions and bathymetry } \\
\cline { 3 - 6 } & & $H_{r m s, o f f}(\mathrm{~m})$ & $T_{p}(\mathrm{~s})$ & $\theta_{\text {off }}$ & Profile \\
\hline 9156 & 17 October, 12h & 1.73 & 7.4 & $39^{\circ}$ & 16 October \\
9160 & 17 October, 17h & 1.31 & 6.2 & $36^{\circ}$ & 18 October \\
9180 & 18 October, 12h & 1.25 & 8.4 & $36^{\circ}$ & 18 October \\
\hline
\end{tabular}




\subsection{Methodology}

The equations (1), (2), (5), (6), (7) and (9), which govern this morphodynamic system, together with the parameterizations used, define a closed dynamical system for the variables $v_{l}, v_{2}, z_{s}, E, E_{r}, \Phi$ and $z_{b}$. The stability analysis approach to the formation of bars by self-organization starts by defining a steady and alongshore uniform basic state (i.e., without longshore rhythmic topography). In this study, we used reference profiles, $\mathrm{z}_{\mathrm{b}}^{\mathrm{o}}(\mathrm{x})$, measured in the Dutch coast, which showed two well-developed shore-parallel bars. The modeled basic state is characterized by the presence of a longshore current, $v_{1}^{o}=0$ and $v_{2}^{o}=V^{o}(x)$, and an elevation of the mean sea level, $z_{s}^{o}=z_{s}^{o}(x)$. This basic state only represents a morphodynamic

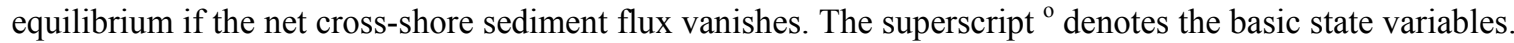

Once the basic state has been computed and validated with field observations, the linear stability analysis can be applied in a standard way. A small perturbation, assumed to be periodic in time and in the alongshore coordinate, is added to this state,

$$
\left(v_{1}, v_{2}, z_{s}, E, E_{r}, \Phi, z_{b}\right)=\left(0, V^{o}, z_{s}^{o}, E^{o}, E_{r}^{o}, \Phi^{o}, z_{b}^{o}\right)+\mathfrak{R} e\left\{e^{(\omega t+i \kappa y)}\left(u, v, \eta, e, e_{r}, \phi, h\right)\right\}
$$

where $\kappa$ is the longshore wavenumber and $\omega$ a complex growth rate. By inserting equation (12) in the governing equations and linearizing with respect to the perturbations, we arrive at an eigenproblem. For each $\kappa$, different eigenvalues $\omega$ exist, which characterize the different growing modes, and the complex eigenfunctions are $\left(u(x), v(x), \eta(x), e(x), e_{r}(x), \phi(x), h(x)\right)$. The growth rate of the emerging bars is given by $\Omega=\boldsymbol{\nabla}(\omega)$, so that $\Omega>0$ means growth. In case of an unstable basic state, solutions with $\Omega>0$ are found and the growth rate curves show these positive $\Omega$ for different values of $\kappa$. Starting from arbitrary initial conditions, the dynamics after some time will be dominated by the mode with largest growth rate, which is called Fastest Growing Mode (FGM). Its $e$-folding growth time is given by $T_{g}=1 / \Omega$ and the migration speed by $c=-a(\omega) / \kappa$. The alongshore wavelength of the corresponding bar system is $\lambda=2 \pi / \kappa$ and the shape of the final topography and the associated quantities are given by equation (12).

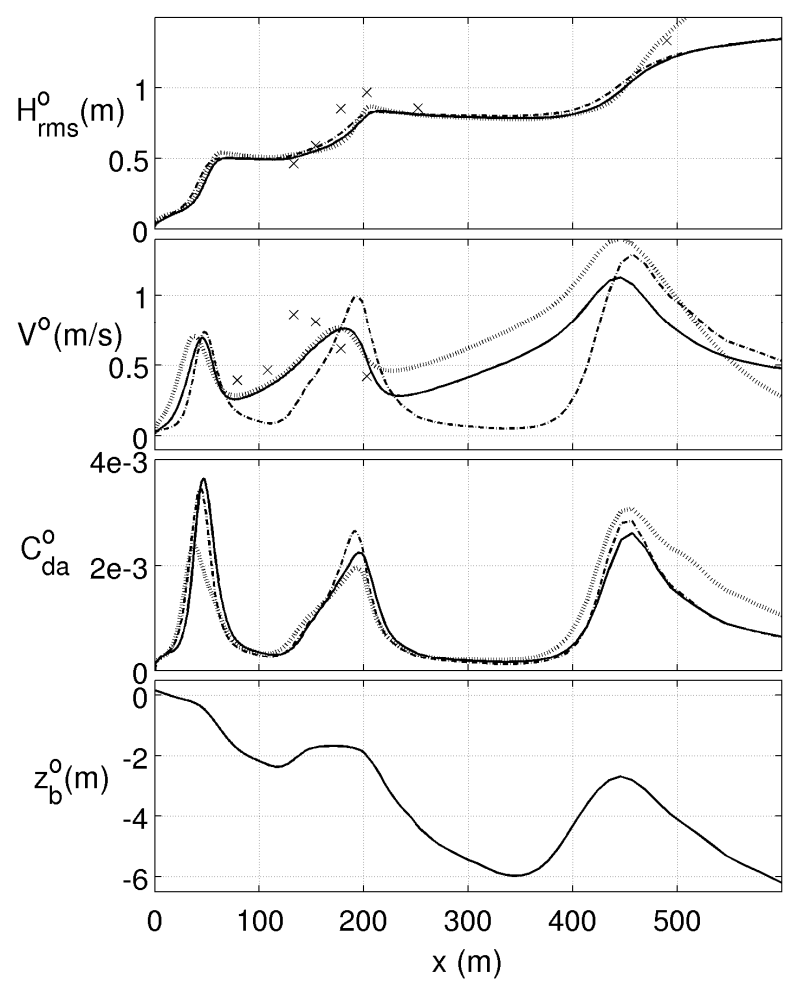

Figure 2. Model results of the basic state at Egmond beach obtained for the conditions of burst 9156 (table 1) with different model configurations: a) using $D_{w}{ }^{a}$ and including the rollers (solid lines), b) using $D_{w}{ }^{b}$ and including the rollers (dotted lines), and c) using $D_{w}{ }^{b}$, and excluding the rollers (dot-dashed lines). The crosses denote the data. 


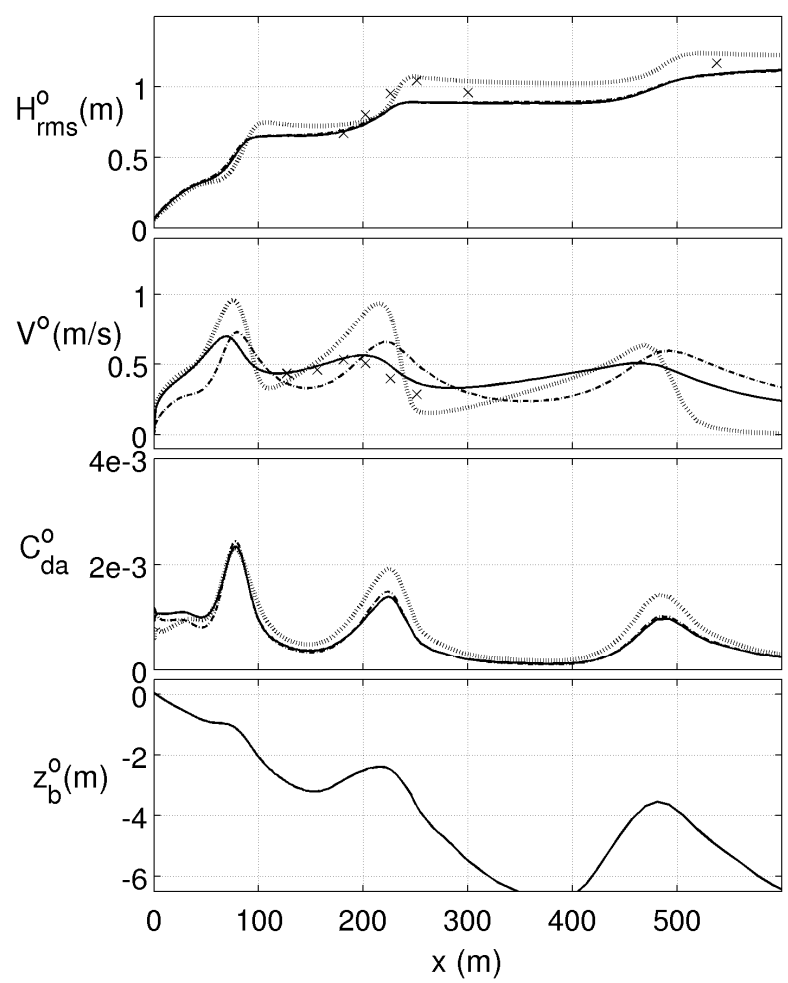

Figure 3. Model results of the basic state at Egmond beach obtained for the conditions of burst 9160 (table 1) with different model configurations. See the caption of figure 1 for more details.

\section{Modelling the longshore current and wave height distributions}

In order to validate the reference basic state, the model was firstly applied to the conditions measured at Egmond beach (the Netherlands) during an intense field campaign performed in October and November 1998. No measurements of the distribution of the longshore current and the wave height were available for Noordwijk site. Egmond site is a very similar beach (located only some $50 \mathrm{~km}$ northward from Noordwijk). Alongshore irregularities were present in the Egmond bathymetry during the whole campaign but they were less pronounced during the first ten days (Ruessink et al., 2001). These days were thereby more adequate to compare with our alongshore uniform results. In particular, we selected three specific bursts of data with offshore $H_{r m s, o f f}$ of the order of $1 \mathrm{~m}$, in order to be in the range of wave conditions needed for transverse bar formation (table 1). These bursts were also selected by Ruessink et al. (2001) to show the details of their comparison with model results (see figure 6 of that paper).

The first step was selecting the model setup that best reproduced the cross-shore distribution of $H_{r m s}^{o}(x)$ and $V^{o}(x)$. Figures 2, 3 and 4 show the modeled $H^{o}{ }_{r m s}(x), V^{o}(x)$ and the measured profile, $z_{b}^{o}(x)$, for the three bursts of table 1 . These figures also display a panel with the depth-averaged sediment concentration, $C^{o}{ }_{d a}(x)=C^{o}{ }_{d i}(x) / D^{o}(x)$, where $C^{o}{ }_{d i}(x)$ is calculated with equation (11). Results are shown for three model setups: a) using the default wave energy dissipation, ${{ }_{\alpha}}_{v}{ }^{a}$, and including the rollers (solid lines), b) using the default dissipation, $\star_{v}^{a}$, and excluding the rollers (dot-dashed lines), and c) using the secondary wave energy dissipation, $\star_{x}^{b}$, and including the rollers (dotted lines). The default value was used for the rest of the model parameters.

Taking the roller dynamics into account is essential in order to accurately reproduce the cross-shore distribution of $V^{o}$, as arises from a comparison of the solid lines and the dot-dashed lines in the three figures. This result agrees with that of Ruessink et al. (2001). Including the roller dynamics causes a lag between the dissipation of wave energy and the transfer of momentum to the water column, and thus an onshore shift in the location of the maximum wave forcing and the maximum longshore current (Svendsen, 
1984). The effect of varying the formulation for the wave energy dissipation is less strong. In bursts 9156 and 9180, the cross-shore distribution of both $H^{o}{ }_{r m s}$ and $V^{o}$ is very similar for the two formulations used, at least in the locations of the six shallower measuring points (over the inner bar and trough). However, the longshore current $V^{o}(x)$ measured in burst 1960 (figure 3) was significantly better reproduced with the default wave energy dissipation, $\Phi_{v}^{a}$. The fact that we used the same bursts as Ruessink et al. (2001) for this detailed comparison, allowed us to compare our results not only with the Egmond data but also with the results of their model (which was very carefully calibrated). The longshore current distribution modeled with ${ }_{\Sigma_{v}}{ }^{a}$ is similar to the $V^{o}(x)$ obtained by Ruessink et al. (2001) in the three bursts. In general, the wave energy dissipation formula $\star_{v}^{b}$ gives a too pronounced dissipation in narrow cross-shore distances (i.e. see the dotted line in the $H_{r m s}^{o}$ panel of figure 3), which subsequently causes the longshore current distribution to become too peaky. Our result is in agreement with Apostos et al. (2007), which compared data of the Duck site (U.S.A.) and model results for different energy dissipation formulae (including $\Sigma_{v}{ }^{a}$ and ${\Sigma_{v}}^{b}$ ), and obtained the smallest rms discrepancies using ${ }_{\alpha_{w}}^{a}$. For the specific conditions used here, the $C^{o}{ }_{d a}(x)$ was qualitatively similar in the three model configurations (figures 2, 3 and 4).

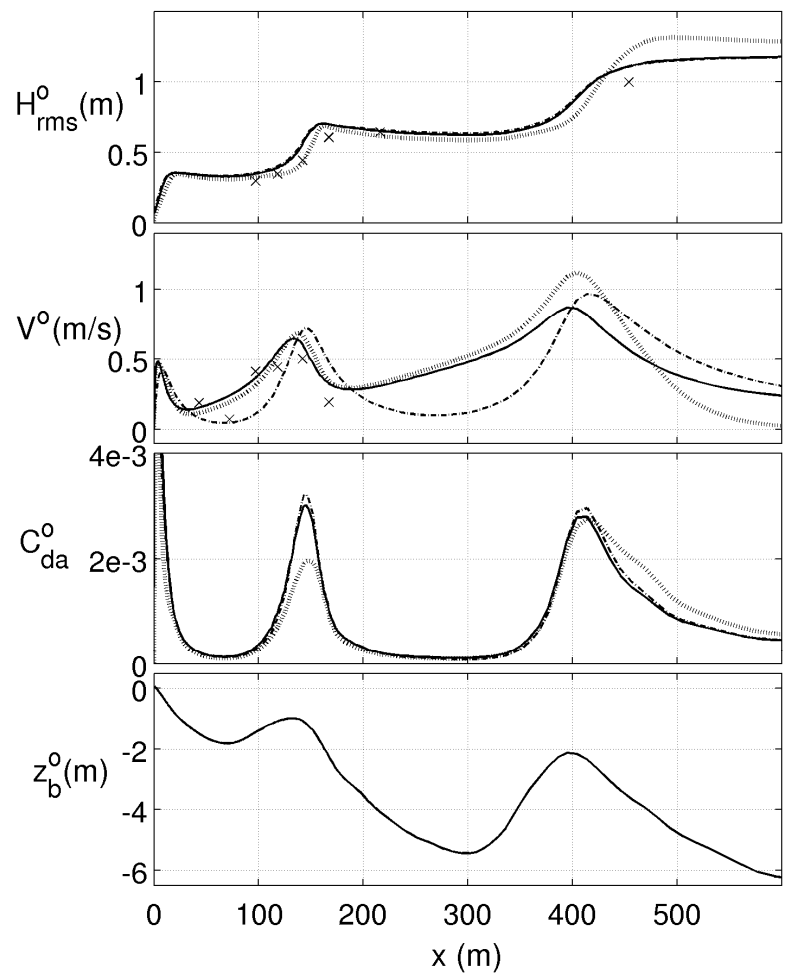

Figure 4. Model results of the basic state at Egmond beach obtained for the conditions of burst 9180 (table 1) with different model configurations. See the caption of figure 1 for more details.

Table 2. Default parameter setting (when using ${\otimes_{w}}^{a}$ of equation 3).

\begin{tabular}{|c|l|c|}
\hline Parameter & Meaning & Value \\
\hline$k_{a}$ & Bed roughness & $0.022 \mathrm{~m}$ \\
$B$ & Dissipation parameter in ${\otimes_{w}}^{a}$ & 1 \\
$\gamma_{b}$ & Coefficient of saturation in ${ }_{\alpha_{w}}{ }^{a}$ & 0.45 \\
$\beta$ & Slope of the roller/wave front & 0.05 \\
$d_{50}$ & Sediment grain size & $0.2 \mathrm{~mm}$ \\
$\varepsilon_{b o r}$ & Suspended load efficiency related to & 0.025 \\
& bore-induced turbulence & \\
\hline
\end{tabular}




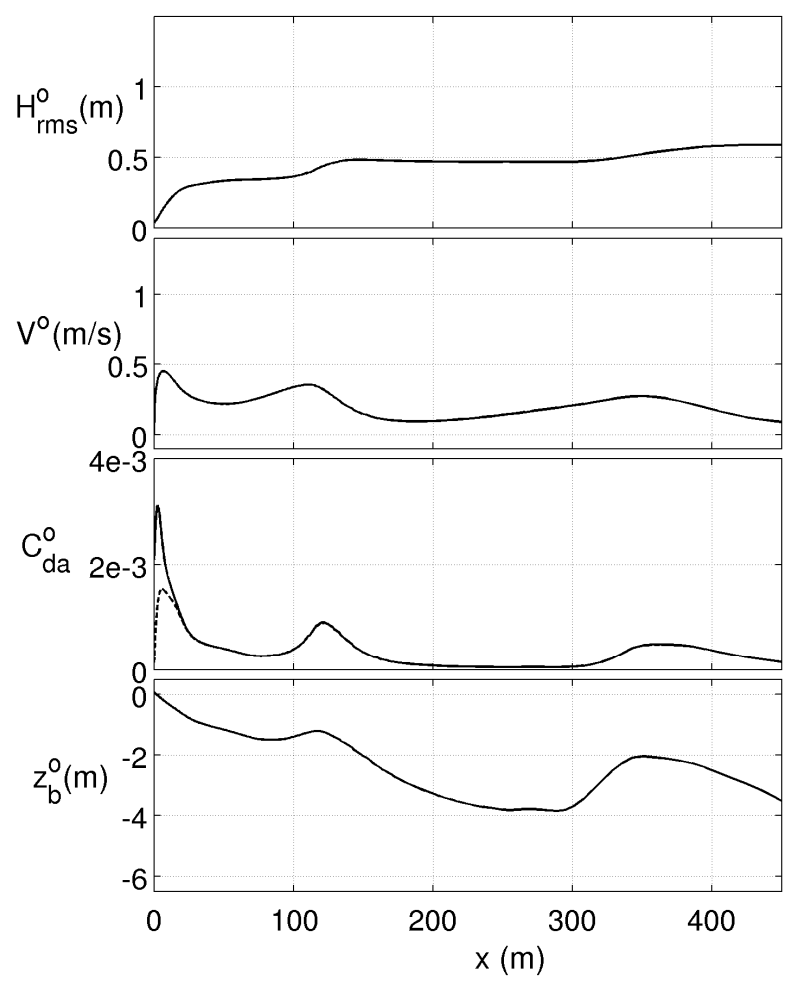

Figure 5. Model results of the basic state at Noordwijk beach obtained for the conditions measured during an event of development of an up-current bar patch on August and September 2002. The solid line in the $C_{d a}^{o}$ panel is obtained for $\varepsilon_{b o r}=0.025$ and the dashed line is obtained for $\varepsilon_{b o r}=0$ (original Sousby van Rijn formula).

\section{Modeling the formation of up-current oriented bars}

After the validation of the basic reference state, the model was applied to the specific wave and bathymetric conditions measured at Noordwijk during the up-current bar event that occurred in AugustSeptember 2002 (see figure 1). The model setup and parameter values were those better reproducing Egmond data: we employed the wave energy dissipation ${ }_{\alpha_{w}}{ }^{a}$, we included the roller dynamics and we used the parameter values in table 2. The profile at $y=-500 \mathrm{~m}$ of the bathymetric survey from 3 October 2002 was used as reference profile. The offshore wave conditions applied were the values obtained after averaging along the duration of the event, $H_{r m s, o f f}=0.72 \mathrm{~m}, T_{p}=5.6 \mathrm{~s}$ and $\theta_{\text {off }}=47^{\circ}$. Two different values for the efficiency $\varepsilon_{b o r}$ were used to calculate $C_{d a}^{o}$ in equation (11), the default value $\varepsilon_{b o r}=0.025$ and $\varepsilon_{b o r}=0$ (i.e., original Soulsby van Rijn formula). Figure 5 shows, from top to bottom, the modeled $H_{r m s}^{o}(x), V^{o}(x)$ and $C_{d a}^{o}(x)$, together with the measured profile, $z_{b}^{o}(x)$. The depth-averaged sediment concentration obtained with the two possible values of $\varepsilon_{b o r}$ diverge significantly in the inner surf zone, as shown in the $C_{d a}^{o}$ panel (compare the solid line with the dashed line in the first 30 cross-shore meters).

When the original Soulsby van Rijn $C_{d a}^{o}$ was used $\left(\varepsilon_{b o r}=0\right)$, the linear stability analysis always lead to negative growth rates. Thereby, the $C_{d a}^{o}(x)$ shown in dashed line in figure 5 was not adequate to model the formation of Noordwijk bars. Only when we included the bore induced sediment resuspension, with the $C_{d a}^{o}(x)$ decreasing seaward across most of the inner surf zone (solid line in figure 5), realistic positive growth rates were obtained. The result of the linear stability analysis obtained for the default parameter setting $\left(\varepsilon_{b o r}=0.025\right)$ is shown in figure 6 , the growth rate curve in the upper left panel and the migration rate curve in the upper right panel. The growth rate curve shows a clear maximum for $\kappa=0.12 \mathrm{~m}^{-1}$, which corresponds to a wave length $\lambda=52 \mathrm{~m}$, an $e$-folding growth time $T_{g}=13 \mathrm{~h}$ and a migration rate $c=70 \mathrm{~m} / \mathrm{d}$. The lower panel in figure 6 displays the shape of the topographic perturbation corresponding to this fastest growing mode. In this panel, waves approach the coast from the bottom left corner so the induced mean longshore current is directed from left to right. The small arrows indicate the main trend in the deviations 
of the longshore current due to the hydrodynamic circulation induced by the growing bars. As can be seen, the solution consists of a patch of up-current oriented bars, whose crests deviates some $60^{\circ}$ from the shorenormal, with current perturbations deflecting offshore over their crests. In order to visualize the final shape of the bottom, the reference profile, $z_{b}^{o}$, should be added. The same applies to the flow: the longshore current $V^{o}$ should be added to the perturbations of the velocity to obtain the total flow.

The predicted wave length is in good agreement with the observed event-averaged value, $\lambda=45 \mathrm{~m}$ (Ribas and Kroon, 2007). The angle of deviation of the bar crests from the shore-normal is smaller in the observations, with values of some $30^{\circ}$ (see figure 1 ). The predicted migration rate is some 3 times larger than the maximum rate detected in the field and one order of magnitude larger than the event-averaged rate $(22 \mathrm{~m} / \mathrm{d}$ and $3.8 \mathrm{~m} / \mathrm{d}$, respectively). Measuring the growth rate of the bars observed in the field was not possible due to the nature of the detection technique (video imaging). However, it could be established that bar emerged in less than 1 day, well within the modeled time for growth. The similarities between the model results and the Noordwijk bars indicate that the bed-flow interaction, first described in Ribas et al. (2003), might cause the development of transverse bars in Noordwijk, and that the bore induced resuspension can be an explanation for the cross-shore distribution of $C_{d a}^{o}$ needed to obtain bar formation.

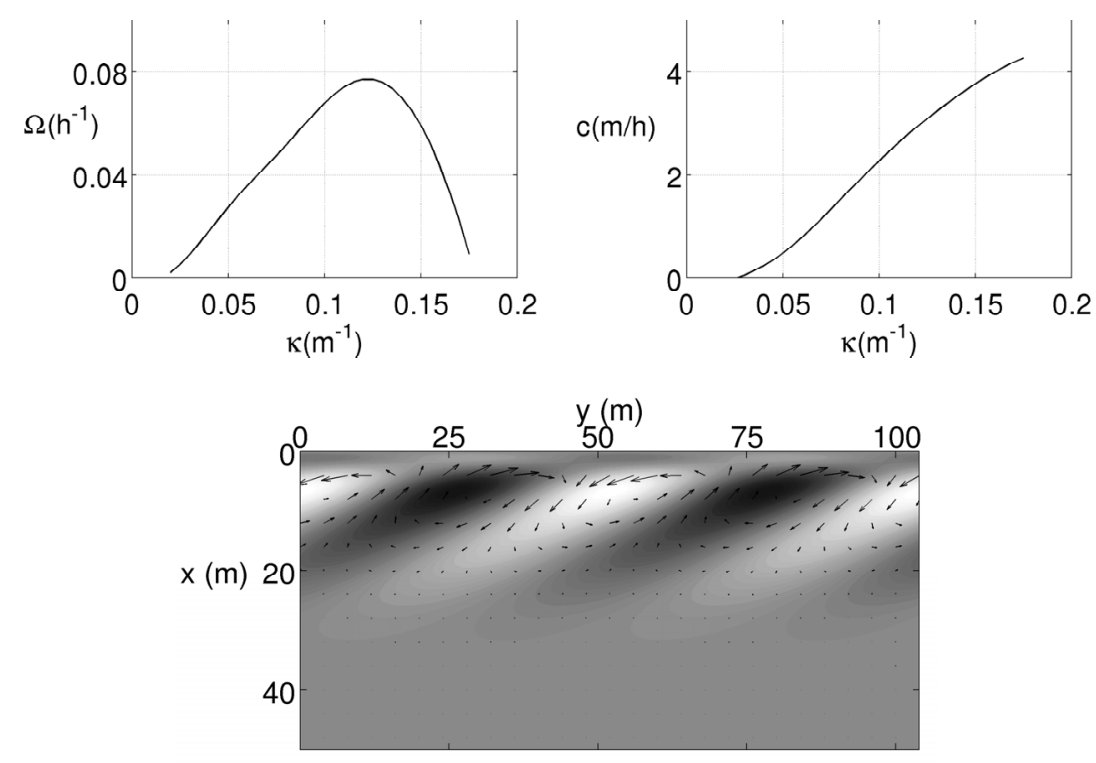

Figure 6. Result of the linear stability analysis obtained when the model is applied to the conditions measured at Noordwijk site during event of development of an up-current bar patch on August and September 2002. The upper panels show growth rate $\Omega$ versus longshore wavenumber $\kappa$ (left) and migration rate $c$ versus $\kappa$ (right). The lower panel plots the topographic perturbation corresponding to the FGM, where white areas indicate crests and dark areas represent troughs. Waves approach the coast from the bottom left corner, so the equilibrium longshore current $V^{0}$ is directed from left to right, and small arrows indicate the current perturbations. 


\section{Conclusions}

The roller dynamics play an essential role in the formation of up-current oriented bars for two reasons. Firstly, they cause an onshore shift in the location of the maximum wave forcing and hence of the peak of the longshore currents. Only when they are included, the modeled cross-shore distribution of the longshore current accurately compares with measured data at Egmond site. Secondly, the rollers create turbulent bores that can lead to significant sediment resuspension in the inner surf zone. This gives a cross-shore distribution of the depth-averaged volumetric sediment concentration that can explain the formation of upcurrent bars at Noordwijk site.

Indeed, realistic positive feedback leading to formation of bars like those observed only occurs if the stirring of sediment due to bore turbulence is included in the model. In that case, the depth-averaged sediment concentration decreases seaward across most of the inner surf zone, which, in combination with an offshore-directed flow over the bars, leads to accumulation of sediment in the crest areas. The upcurrent oriented shape, the wavelength (around $50 \mathrm{~m}$ ) and the growth rate (of the order of half a day) of the modeled bars are in good agreement with observations at Noordwijk. However, modeled migration speeds (several tens of meters per day) are significantly higher than those measured in the field.

\section{Acknowledgements}

Funding from the Spanish research project `Morfodinámica de playas: predicciones en las grandes escalas espacio-temporales' (contract CTM2006-08875/MAR) is acknowledged. Data collected at Egmond were kindly provided by Dr. Gerben Ruessink. The authors also thank partial funding from the ETSECCPB of the Universitat Politècnica de Catalunya (Spain).

\section{References}

Apostos, A., Raubenheimer, B., Elgar, S., Guza, R.T., and Smith, A. (2007). Effects of wave rollers and bottom stress on wave setup. J. Geophys. Res., 112:C20003, doi:10.1029/2006JC003549.

Calvete, D., Dodd, N., Falqués, A. and van Leeuwen, S.M., 2005. Morphological development of rip channel systems: Normal and near normal wave incidence. J. Geophys. Res., 110:C10006, doi:10.1029/2004JC002803.

Church, J. C. and Thornton, E. B., 1993. Effects of breaking wave induced turbulence within a longshore current model. Coastal Eng. 20:1-28.

Feddersen, F., Guza, R.T., Elgar, S. and Herbers, T.H.C., 2000. Velocity moments in alongshore bottom stress parameterizations. J. Geophys. Res., 105(C4):8673-8686.

Garnier, R., Calvete, D., Falqués, A. and Caballeria, M., 2006. Generation and nonlinear evolution of shoreoblique/transverse sand bars. J. Fluid Mech., 567:327-360.

Gelfenbaum, G. and Brooks, G.R., 2003. The morphology and migration of transverse bars off the west-central Florida coast. Mar. Geol., 200:273-289.

Kobayashi, N., Payo, A. and Schmied, L., 2008. Cross-shore suspended sand and bed load transport on beaches. $J$. Geophys. Res., 113:C07001, doi:10.1029/2007JC004203.

Konicki, K.M. and Holman, R.A., 2000. The statistics and kinematics of transverse bars on an open coast. Mar. Geol., 169:69-101.

Reniers, A.J.M.H., Roelvink, J.A. and Thornton, E.B., 2004. Morphodynamic modeling of an embayed beach under wave group forcing. J. Geophys. Res., 109:C01030, doi:10.1029/2002JC001586.

Ribas, F., Falqués, A. and Montoto, A., 2003. Nearshore oblique sand bars, J. Geophys. Res., 108:C43119, doi:10.1029/2001JC000985.

Ribas, F., Swart, H.E., Calvete, D., Falqués, A., Dodd, N. and van Leeuwen, S., 2005. Sensitivity of modeled nearshore morphology to wave and sediment transport formulations. In Coastal Dynamics 2005. Am. Soc. of Civ. Eng.

Ribas, F. and Kroon, A., 2007. Characteristics and dynamics of surfzone transverse finger bars, J. Geophys. Res., 112: F03028, doi:10.1029/2006JF000685.

Roelvink, J.A., and Stive, M.J.F., 1989. Bar-generating cross-shor flow mechanisms on a beach. J. Geophys. Res., C94: 4785-4800.

Ruessink, B. G., Miles, J.R, Feddersen, F., Guza, R.T. and Elgar S, 2001. Modeling the alongshore current on barred beaches. J. Geophys. Res., 106(C10):22451. 22463.

Soulsby, R. L., 1997. Dynamics of Marine Sands. London, U.K.: Thomas Telford. 
Thornton, E.B., and Guza, R.T. (1983). Transformation of wave height distribution, J. Geophys. Res., C88: 5925-5938. Svendsen, I.A., 1984. Wave heights and setup in the surf zone, Coast. Eng., 8:303-329.

van Enckevort, I. M. J., Ruessink, B.G., Coco, G., Suzuki, K, Turner, I.L., Plant, N.G., and Colman, R.A., 2004. Observations of nearshore crescentic sandbars. J. Geophys. Res., 109:C06028, doi:10.1029/2003JC002214.

Voulgaris, G., and Collins, M.B., 2000. Sediment resuspension on beaches: response to breaking waves. Mar. Geol., 167:167-187.

Wright, L.D., and Short, A.D., 1984. Morphodynamic variability of surf zones and beaches: A synthesis. Mar. Geol., 56:93-118. 